\title{
Mutasyon (Ses Değişimi) Döneminde Seslerin Sınıflandırılması
}

\author{
Satı DOĞANYİĞİT \\ Kırşehir Ahi Evran Üniversitesi \\ sati-dgnygt@hotmail.com \\ ORCID ID: 0000-0003-2246-5207
}

Derleme Makale

DOI: $10.31592 /$ aeusbed.681306

Geliş Tarihi: 28.01.2020

Revize Tarihi: 12.10.2020

Kabul Tarihi: 30.10 .2020

\section{Atıf Bilgisi}

Doğanyiğit, S. (2020). Mutasyon (ses değişimi) döneminde seslerin sınıflandırılması. Ahi Evran Üniversitesi Sosyal Bilimler Enstitüsü Dergisi, 6(3), 991-1010.

\section{ÖZ}

\begin{abstract}
Mutasyon (ses değişimi) ergenliğin başlamasıyla birlikte vücuttaki diğer değişimlere paralel olarak seste de dramatik bir değişim sürecinin yaşandığı dönemdir. Ses karakterinin şekillenerek kimlik kazandığı bu süreçte çeşitli zorluklarla karşılaşılabilir. Vokal organlardaki büyüme her bireyde aynı oranda gerçekleşmediği için sesin kontrolü de zorlaşmaktadır. Bu dönemde yaşanan zorlukları ve sesin özelliklerini bilmek uygun yaklaşım sergilemek açısından oldukça önemlidir. Doğru yaklaşım sergilenmediği taktirde seste kalıcı hasarlar oluşabilir ve öğrenciler şarkı söylemekten uzaklaşarak bu derslerden kopabilirler. Ses değişimi kişiden kişiye farklılık göstermekte, aynı sınıfta farklı evreleri yaşayan öğrencilere rastlanabilmektedir. Bu sebeple sesin bulunduğu evreyi tespit etmek ve uygun bir şekilde sınıflandırmak önemlidir. Mutasyon sürecine kadar çocuk sesleri alto veya soprano olarak sınıflandırılmaktadır. Ancak bu geçici evrede çocuk seslerinin kadın ya da erkek ses özelliklerini kazanıncaya kadar yeni bir sınıflandırmaya tabi tutulması gerekmektedir. Bu derlemede mutasyon dönemindeki çocukların seslerinin nasıl sınıflandırıldığı üzerinde durulmaya çalışılmıştır. Ses değişim evrelerine uygun bir sınıflandırma yöntemi kullanılmasının önemi ortaya çıkmıştır. Müzik derslerinden verim elde edilmesi ve öğrencilerin gereken kazanımları elde edebilmeleri açısından bu durum gerekli görülmektedir.

Anahtar Kelimeler: Ses değişimi, seslerin sınıflandırılması, mutasyon dönemi, müzik eğitimi, ergenlik dönemi.
\end{abstract}

\section{Classification of Voice in the Period of Mutation (Voice Change)}

\begin{abstract}
The mutation (voice change) is the period in which a dramatic change in the voice is experienced in parallel with the other changes in the body with the onset of adolescence. In this challenging period in which the character of voice is shaped and formed, persons encounter various difficulties. As the growth of vocal organs does not occur at the same rate in every individual, the control of the voice becomes difficult. In this period, knowing both of the difficulties and the characteristics of the sound are very important in terms of showing an appropriate approach. If the correct approach is not shown, voice change may cause permanent damages in the sound and even students may get disconnected from music lessons by getting away from singing. The voice change varies from person to person, and students at different stages of the process can be found in the same class. Therefore it is important to identify the stage of voice mutation and to classify the voice appropriately. In this review, we dwelled on how the voices of children in the mutation period are classified. The importance of using a classification method suitable for the stages of voice change has emerged. This is essential in order to obtain efficiency from the music courses and to provide a suitable conditions to students to obtain necessary gains.
\end{abstract}

Keywords: sound change, voice classification, mutation period, music education, adolescence period.

\section{Giriş}

Ergenlik, fizyolojik ve ruhsal değişikliklerin başlamasıyla birlikte çocukluktan yetişkinliğe geçişte dramatik etkilerin yaşandığı aşamaları içeren bir dönem olarak adlandırılabilir. Değişim kadın ve erkek cinsiyet karakterlerinin oluşması ile sürecini tamamlar. $\mathrm{Bu}$ dönemde vücuttaki diğer değişimlere paralel olarak larenkste de büyüme meydana gelir. Ses tellerindeki bu büyümenin sonucu olarak ses, değişim sürecine girer ve cinsiyet açısından kadın ve erkek sesi olarak sınıflandırılır. Ergenliğin başlangıcından bitimine kadar geçen sürede insan sesi çeşitli aşamalardan geçer. Bu dönem her ne kadar geçici olsa da müzik eğitimi açısından azımsanmayacak bir süreyi kapsamaktadır. $\mathrm{Bu}$ anlamda sesleri, dönemin ses özelliklerine göre sınıflandırma gerekliliği ortaya çıkmaktadır. 
Her ne kadar ses değişimi erkek çocuklarda belirgin bir şekilde kendini gösterse de kızlar da aynı değişim sürecinden geçer ve benzer problemleri yaşar. Ancak kızların problemleri ile başa çıkmak daha kolaydır. Çünkü ses telleri Cevanşir ve Gürel'e (1982) göre erkeklerde 1cm, kızlarda 3-4 mm uzar ve geniş̧lik kazanır. Bu değişime paralel olarak sesteki pesleşme erkeklerde bir oktav iken kızlarda 1/3 oktavdır (Çevik, 1999). Bu durum ise şark1 söylenebilecek olan ranj ve tessituray1 doğrudan etkilemektedir. Bu sebeple uygun ranj ve tessituraya sahip eserler seçmek ve sesleri doğru siniflandirmak önem arz etmektedir.

Ortaokul yıllarına rastlayan bu özel dönemde öğretmenlerin yapabileceği en büyük hata, ergen şarkıcılara yetişkin terminolojisi ve sınıflandırması uygulamaktır. $\mathrm{Bu}$ sadece seslerin yanlış sınıflandırılmasına ve eser seçiminde yanlış uygulamalara yol açacaktır (Collins, 1987). Her erkek ergenin ranjını, değişiklik boyunca düzenli ses kontrolleri ile belirlemek önemlidir. Erkekler ses değişim sürecine girdiklerinde değişimin hangi aşamasında oldukları belirlenerek uygun bir partiye yerleştirilmeli, uygun ranj ve tessiturada şark1 söylemelidirler (Busch, 1973; Collins, 2012). Bir koro şefi veya müzik öğretmeni bu konuda oldukça dikkatli davranmalı ve sesin o anda bulunduğu kalite ve ranjına göre sınıflandırmanın ötesinde ergenlik sonrası dönemi hakkında da öngörü sahibi olmalıdır (Busch, 1973).

Ortaokullarda ve lisenin belli bir dönemine kadar (mutasyon süreci lisenin ilk yıllarına kadar devam edebilmektedir) verilen müzik eğitiminde bazı geleneksel yaklaşımların gözden geçirilmesi gerekmektedir. Sesin önemli bir değişim ve dönüşüm aşamasına girdiği bu dönemde her öğrencinin sesi kendi yapısal gelişimine göre de şekilleneceği için aynı sınıfta değişimin farklı evrelerinde yer alan öğrencilere sık rastlanması olasıdır. Bu durumda sağlıklı bir eğitim ortamı oluşturmak ve öğrencilerin seslerine zarar vermeden performans sergilemelerini sağlamak müzik öğretmenleri açısından zorlayıcı olduğu kadar önemli bir görevdir.

Mutasyon dönemi erkeklerde kızlara göre daha açık belirtilerle kendini gösterdiği için uzun yıllar kızların seslerinde meydana gelen değişim fark edilmemiş ve bu nedenle erkek çocuklara kıyasla daha az araştırılmıştır. Ulaşılabilen literatürün erkek çocuklar açısından zengin olması ve sınıflandırma yöntemlerinin çoğunlukla erkekleri kapsaması bu sebepledir. Çalışmada mutasyon döneminde sesleri sınıflandırma yöntemleri analiz edilmiş, müzik eğitimi açısından sınıflandırmanın gerekliliği tartışılmıştır.

\section{Yöntem}

$\mathrm{Bu}$ çalışma mutasyon döneminde seslerin nasıl sınıflandırıldığı konusunda farklı yöntemlerin kronolojik ve metodolojik olarak bir araya getirilerek sunulması amacıyla yapılmış bir derleme araştırmasıdır. JSTOR Veri Tabanı, Cambridge Journals Online Veri Tabanı, Google Akademik, Research Gate, Google Arama Motoru ve Yükseköğretim Kurulu (YÖK) lisansüstü tez veri tabanları üzerinde; ses değişimi, ses değişimi döneminde seslerin sınıflandırılması, ses değişimi döneminde seslerin özellikleri, mutasyon dönemi anahtar kelimeleri Türkçe ve İngilizce kullanımları ile taranmış ve ulaşılabilen 335 kaynak incelenmiştir. İncelenen kaynakların konuya ilişkin olanları belirlenmiştir. Belirlenen bu kaynakların büyük çoğunluğunun altı çalışmaya işraret ettiği, bu çalışmaların ise çok sayıda atıf aldığı ve çok sayıda çalışma grubu ile yıllar süren araştırmalar neticesinde ortaya çıkan verilerle mutasyon döneminde sesleri sınıflandırma yöntemlerinin geliştirildiği, günümüzde halen tez, makale vb. yayınlarda (Denison, 2015; Freer, 2008; Friddle, 2005; Gebhardt, 2016Hall, 2009; Hook, 2005;Looney, 2015; Nguyen, 2015; Sassi, 2009; Skelton,2007; Stockton, 2014; Stockton, 2015; Sweet, 2015; Thurman, 2012; Tomb, 2012) sıklıkla başvurulduğu veya konu olduğu görülmektedir. $\mathrm{Bu}$ sebeplerle çalışmada altı yöntem incelenerek analiz edilmiştir.

Çalışmada sınıflandırma yöntemleri incelenirken notasyon konusunda ortak bir dil geliştirmesi gerekliliği ortaya çıkmıştır. Bu amaçla notaların frekanslarını göstermek için; subkontra, kontra, büyük, küçük, birinci, ikinci, üçüncü, dördüncü, beşinci oktav olarak adlandırılan aşağıdaki sistem kullanılmıştır. 


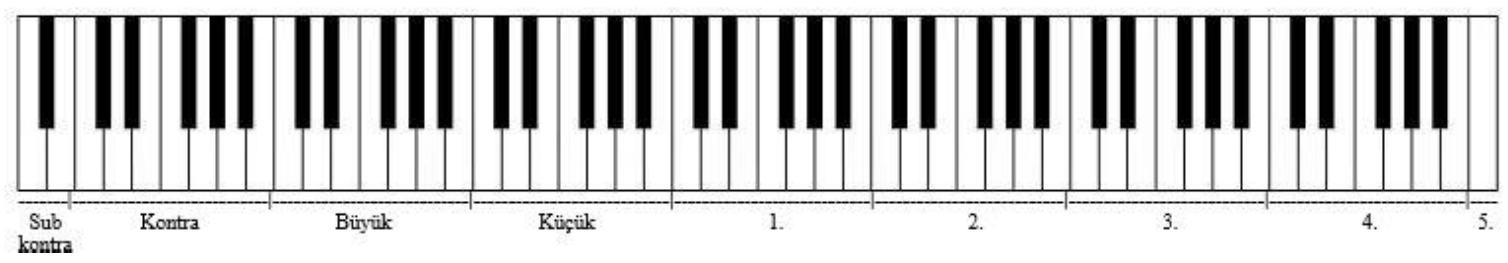

Şekil 1. Ses dizisinde yer alan oktavların isimleri ve yerleri (Elhankızı, 2012). Uygulamalı temel müzik bilgileri, Konya, Eğitim Kitabevi).

\section{Mutasyon Döneminde Seslerin Sınıflandırma Yöntemleri}

$\mathrm{Bu}$ bölümde mutasyon döneminde seslerin sınıflandırılmasına ilişkin yapılmış olan çalışmalar incelenerek, sınıflandırılmasında kullanılan yöntemler kronolojik ve metodolojik olarak sunulmuştur.

\section{Elsie M. Shawe'in Mutasyon Dönemi Ses Sınıflandırma Yöntemi}

Okullarda 12 yaş ve üstü öğrencilerin test edilmesi ve sınıflandırılması, sadece okutulan müzik partilerinin müzikal olması açısından arzu edilen bir şey değil, aynı zamanda erkek ve kızların vokal organlarının korunması için de bir zorunluluktur. Bu sebeple sesleri değişen ya da değişme işareti gösteren erkek çocuklara test uygulanmalıdır. Öğrencinin yaşına, cinsiyetine ve fiziksel görünümüne bağlı olarak seçilen bir egzersiz eğer ses henüz değişmemişse Mi Majör tonunda kısa bir (sol-mi-do) motif belirlenerek tiz registere doğru yaklaşık üç tonda tekrar ettirilir. Daha sonra, sol ${ }^{1}$ perdesi üzerinden başlanarak yukarı ve aşağı skalada egzersiz yaptırılır. Sol$^{2}$ üzerinde rahat, parlak ve yumuşak bir ses kalitesi ile egzersizi söyleyebilen öğrenciler birinci soprano partisine verilir. $\mathrm{Mi}^{2}$ üzerinde ve küçük oktav si b'den daha pes alanda rahat söyleyemeyenler ikinci soprano partisine verilirler. Küçük oktav sol ve dizinin bazı derecelerine kadar (sol anahtarının hemen altında bulunan alan) serbest ve açık bir boğaz ile sıcak ve koyu bir renkte ses üretebilen ve $\mathrm{re}^{2}$ ile mi $b^{2}$ üzerinde söyleyebilen sesler birinci alto olarak sınıflandırılır. Daha pes sesler için öğrenciye küçük oktav sol sesi (perdesi) verilir ve perdeden aşağı skalaya doğru egzersizi söylemesi istenir. Eğer alt oktavda söyleyebilirse (büyük oktav sol) öğrenci bas grubuna alınır; eğer sadece küçük oktav mi veya yukarı doğru sol ${ }^{1}$ veya la ${ }^{1}$ e kadar olan alan üzerinde söyleyebiliyorsa öğrenci ikinci alto partisine verilir ve dört partili bir armonide ise tenor partisi olarak verilen bölümü söyler. Küçük oktav fa'dan daha pes şarkılar ikinci altoda kullanılmamalıdır. Dört bölümlü şarkıların çoğunda alto partisi için en pes ses küçük oktav sol'dür. (Shawe, 1916).

Shawe bas erkekler arasında küçük oktav si' de seste çoğunlukla belirgin bir kırılma tespit etmiştir. Bu erkeklerin göğüs sesinde si b'de şarkı söyleyebildiği ve daha tizde şarkı söyleyemediği görülmüştür. Bu tür durumlarda bu baslara ekstra zaman ayırarak rehberlik etmek gerekir. Parlak bir kafa sesi kullanmak için bas anahtarında falsetto ton, küçük oktav mi b, küçük oktav re, küçük oktav re $b$ ve küçük oktav do üzerinde, bu parlak kafa tonları uygulanmalıdır. Bu tonların kısa bir süre sonra karma bir tona dönüştüğü görülecek ve çocuk normal bas sesi genişliğine sahip olacaktır. $\mathrm{Bu}$ çocukların çoğu bir geçiş aşamasında olduğu için mümkün olduğunca, ikinci alto bölümünü bir sömestrde iki kez tekrar test etmek gerekmektedir (Shawe, 1916).

Altıncı sınıfın son yarısında üç partili müziğe başlayan Shawe bu sınıfta çok sayıda alto ses bulamadığını; ikinci soprano bölümünün üst sınıflarda her zaman geniş olduğunu dile getirmiştir. Sınav yapanın yanlış karar vermesi durumunda değişmeyen sesler bu bölümde şarkı söyleyerek yaralanmalara karşı daha az tehlike altında olacağı için bunu akılda tutmak fayda sağlayacaktır. Yedinci sınıfta birinci ve ikinci sopranoları, birinci alto ve birkaç bas ile ikinci altoları tespit eden 
Shawe sekizinci sinifta her zaman birinci ve ikinci soprano, birinci ve ikinci alto ve bas seslere ayrılmış beş ses grubu bulmuştur (Shawe, 1916)

İkinci sopranolar mi $^{2}$ nin üstüne çıkmayan dört bölümlü şarkılarda birinci sopranolar ile şark1 söyler, diğer şarkılarda, birinci soprano, ikinci soprano, birinci alto ve bas için düzenlenmiş şarkıların dışında onlar altolar ile şarkı söyler. Bu son adlandırılan şarkı grubunda birinci ve ikinci altolar aynı partide söyler. Sadece göğüs registerini kullanması için bir kız öğrenci güvenli olmadığı düşünülen ikinci alto partisine hiçbir zaman verilmemelidir. Kızların şarkı söyleme tonu çoğunlukla $\mathrm{fa}^{1}$ in altındaki tonlarda yazıldığı zaman uygun olacaktır (Shawe, 1916).

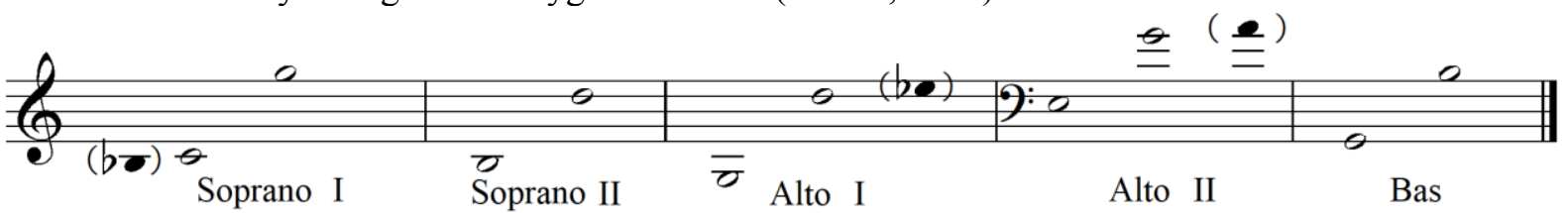

Şekil 2. Mutasyon dönemi ses ranj1 (Shawe, 1916). Voice testing and classification of voices, Music Supervisors' Journal, 2(4), 22- 26.

\section{Irvin Cooper'ın Mutasyon Dönemi Ses Sınıflandırma Yöntemi}

Çoğu ders kitabında değișen ses alto-tenor olarak adlandırılırken Cooper (1950) değişen sesi cambiata olarak adlandırmaktadır. Cambiatanın ses ranjı küçük oktav fa'dan do ${ }^{2}$ ye kadar uzanır. (Cooper, 1950). Cambiata konsepti Amerika Birleşik Devletleri'nde ergenlik dönemindeki erkek çocuklara ses değişimi sırasında şarkı söylemeyi öğretmek için kullanılan ilk metodolojilerden biridir. Cambiata konseptinin kurucusu Irvin Cooper, erkeklerin ses değişikliği sırasında şarkı söyleyebildiklerini keşfetti ve bu çalkantılı dönemde erkeklerin şarkı söylemeye devam etmeleri için bir yöntem geliştirdi. Erkeklerin seslerinin sadece fizyolojik ses aralığının dışındaki şarkıları söylemeye zorlandıkları zaman sesin kırıldığını ve sesin kademeli olarak değiştiğini deneysel çalışmalarla kanıtladı (Stockton, 2015). Cooper hayatı boyunca 114000 ergen sesi ile çalışarak bu özel dönemdeki sesleri sınıflandırmıştır. Çok sayıda ergen ile çalışması ve pratik deneyiminin zenginliği sayesinde bazı ilkeler ortaya çıkmış, ergen seslerinin sınıflandırılması metodunu da geliştirmiştir (Collins, 1982).

Ortaokullarda değişen ses ile çalışırken özellikle de koro çalışmalarında çeşitli problemlerle karşı karşıya kalınmaktadır. Koro sorunlarının çözümü için öğretmene önemli görevler düşmektedir. Öğretmen, soprano, cambiata veya bariton olarak sınıflandırmak üzere erkek çocukların sesinin kalite ve sınırını belirlemeli, onları gruplara bölerek organize etmeli, bu grupları kızların sesleri ile bağdaştırmalı ve bu çeşitli grupların ses sınırlarına uygun şarkı materyallerini seçmelidir. Cooper daima sonuca ulaşan bir sınıflama işlemi sunmaktadır. Erkek çocuklardan tek sesli olarak Mi b Majör tonu kullanılarak "carry me back to old virginny" şarkısını söylemeleri istenir (Ek 1). Bu şarkı bu tonda söylenmek zorundadır, otomatik olarak en rahat oldukları sesleri ile bu şarkıyı söyleyeceklerdir ve bazı erkek çocukların orta do üzerinde söylerken diğer kalanların bir oktav aşağıda söyledikleri fark edilecektir. Öğretmen hızla grup arasında dolaşıp pes sesleri etkin bir şekilde susturup sadece tiz seslerin duyulmasını sağlamalıdır. Susturulanlar baritondur. Cambiata sesleri tespit etmek için, sadece tiz seslerden, bu defa Si b Majör tonu kullanarak aynı şarkıyı söylemeleri istenir. Eğer bunlar arasında soprano sesleri varsa diğerlerinden bir oktav daha tiz şarkı söylemeleri ile çabucak ayırt edilebilirler. Soprano erkek çocukları birer birer susturulduğunda kalanlar cambiatadır (Cooper, 1950).

Koro gruplara göre yeniden organize edilmeli, kızları birinci ve ikinci sopranolar olarak ayırdıktan sonra, Si b Majör tonunda "ah" hecesi söyletilerek koral denge test edilmelidir. Baritonlar küçük oktav si b, cambiatalar fa ${ }^{1}$, ikinci soprano si $b^{1}$ ve birinci soprano re $^{2}$ olarak belirlendikten sonra yapılacak olan bir crescendo ve bir diminuendo, öğrenciler ve öğretmenler için ilk gerçek heyecanı 
sağlayacaktır (Cooper, 1950). Mutasyon dönemi ses sınıflarına göre ses ranj ve tessiturası (tst) aşağıdaki şekilde gösterilmektedir.

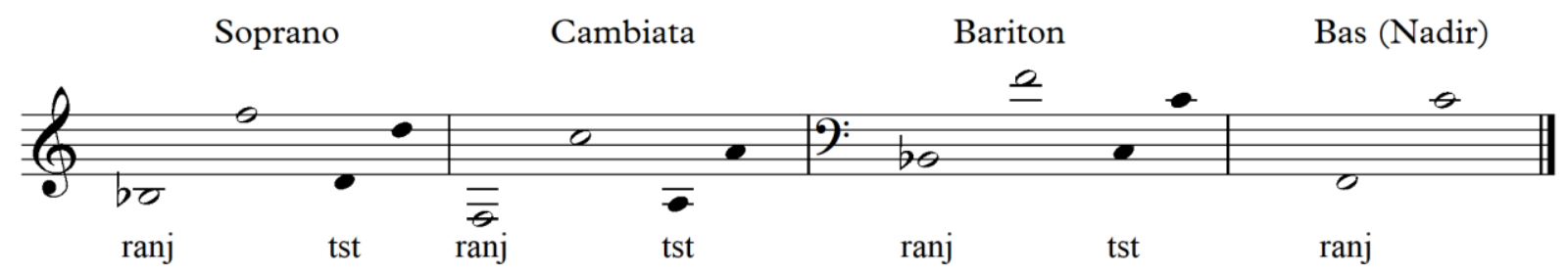

Şekil 3. Mutasyon Dönemi Ses Sinıflarına Göre Ses Ranj1 (Cooper, I. (1950). The high school choral problem, Music Educator Journal, 37(2), 20-21). Robertson, N. L. (1970). A study of the significant contributions of urvin cooper to music education on the junior high school level (Master dissertation, Ouachita Baptist University).

\section{Duncan Mckenzie’nin Mutasyon Dönemi Ses Sınıflandırma Yöntemi}

Mutasyon döneminin başlayacağının ilk belirtisi hemen öncesinde erkek çocuğun soprano tonunun alışılmışın dışında çok güzel bir kalite kazanmasıdır. Bu erkek çocukların sesleri daha dolgun ve daha önce sahip olmadığı bir zenginliğe sahiptir. En parlak tiz notalar sadece daha büyük olan erkek çocuğun sesinde duyulur. Bu ton kalitesi, bir soprano bölümünde duyulduğunda, bazı erkek çocukların ergen evre seviyesine vokal olarak ulaştığının göstergesidir. (McKenzie, 1956).

Mutasyon döneminde erkeklerin yılda en az iki kez bireysel veya gruplar halinde, farklı tonlarda çok uzun olmayan egzersizler kullanılarak (deneme yanılma yoluyla), özellikle dar ranjalı olabilecek erkeklerde bir oktavdan daha az ranja sahip bilindik şarkılar seçilerek test edilmesi gerektiğini belirten McKenzie (1956) bu dönemde sesleri; soprano I, soprano II, alto, alto-tenor olmak üzere dört aşamada sınıflandırmıştır. Alto-tenor, ses değişiminin başlamasıyla birlikte ergen erkeğin pesleşen sesini tanımlamak ve sınıflandırmak için kullanılan bir terimdir. Bu terim, ortaokul ses değişim döneminde bulunan ergenlik çağındaki erkekler için dört bölümlük ses müziğinin üçüncü kısmına uygun bir tanımlama ihtiyacının sonucu olarak ortaya çıkmıştır. Terim sadece sese değil, aynı zamanda partiye de uygulanmıştır. Hala alto olan ses, ergen erkeğin tenor ranjında şarkı söyleyebileceği kadar düşmekle beraber henüz erkeksi bir kaliteye (tenor ya da bas) sahip değildir (McKenzie, 1956).

Küçük oktav sol ile sol ${ }^{1}$ arasındaki bir oktavlık alan alto-tenor ranjı olarak kabul edilmiştir. Okullarda yıllar içerisinde oluşan deneyim ve tecrübe sonucu sesin alto-tenor olarak sınıflandırılmasının güvenilir ve pratik bir yol olduğu ispatlanmıştır. Bazı sesler alto-tenor ses ranjının birkaç nota üstünde tiz veya birkaç nota altında pes okuyabilselerde bu ranj genel bir sınıfın altotenoru için rahattır. Küçük oktav fa'da şarkı söyleme yeteneği alto-tenor aşamasına ulaşıldığının göstergesidir. Ses değişim hızı her ergen erkekte farklı olmakla birlikte genellikle ortaokul yıllarında erkeklerin çoğu bu aşamadan geçer. Ancak yavaş değişen bazı sesler liseye gelene kadar bu aşamaya ulaşamaz. Alto-tenor (ses ve sınıflandırma) bu nedenle özellikle ortaokul dönemiyle ilişkilidir. Ya sesleri hızlıca değiştiği için ya da sesleri yaz tatilinde alto-tenor aşamasından geçtiği için, bazı erkekler sinıflamayı tamamen atlarlar (McKenzie, 1956).

Tenor partisinin büyük ölçüde alto-tenor aralığında olması sebebiyle ortaokulda karma ses için dört partili müziği kullanmak mümkün olabilmiştir. Soprano, alto, alto-tenor ve bas için yazılan dört bölümlük müzik alto-tenorları olmayan yedinci sınıflar hariç ortaokulun tüm seslerine uygundur. Yedinci sınıfta değişen sesler varsa, soprano, alto ve bas için müzik kullanmaktan başka alternatif yoktur. Bununla birlikte, bu üç bölümlük müzik, birçok sesin alto-tenor aşamasına ulaştığı sekizinci ve dokuzuncu sınıflar için uygun değildir (McKenzie, 1956). Mutasyon dönemi ergen erkeklerin ses ranj1 aşağıda gösterilmektedir.

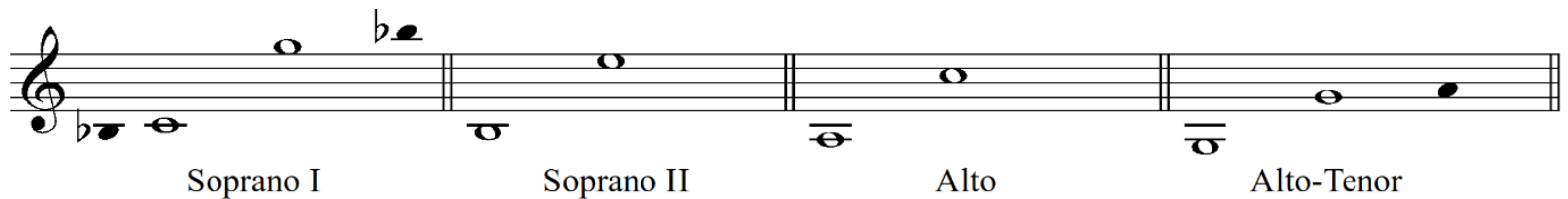


Şekil 4. Mutasyon Dönemi Erkeklerde Ses Ranj1 (McKenzie, D. (1956). Training the boy's changing voice. New Brunswick, NJ: Rutgers University Press).

Mutasyon döneminde bir sesi sınıflandırırken tınıdan çok ranj dikkate alınmalıdır, ancak değişen ses önemli ölçüde geliştiğinde bu kez ranjdan ziyade tını belirleyici faktör olacaktır. Sınıflandırmada ranj ve tını önemli olmakla birlikte psikoljik faktörler ve yaş gibi durumlarda dikkate alınmalıdır. Ergenlik çağındaki bir erkeğin hangi ses sınıfına yerleştirildiği bu açıdan önemlidir. Örneğin; konuşma sesindeki belirtilere göre soprano II olarak sınıflandırılsa da rahat söylediği alan soprano I olabilmektedir veya soprano I söyleyen bir ergen erkek büyük görünüyorsa soprano II olarak sinıflandırmak daha mantıklı olabilmektedir. Bu sayede kendini bu sinıflamada daha iyi hissedeceği gibi değişim de teşvik edilecektir. Ses pesleştikçe Sorano II olarak sınıflandırılmış bir erkek bu ranjın en tiz notalarında şarkı söylemekte zorlanmaya başladığında alto sınıfına aktarılmalıdır. Eğer alto sınıflandırmasında iken, konuşma sesi pesleşmeye başlarsa bu aşamada, onu alto-tenor olarak sinıflandırmak gerekmektedir (McKenzie, 1956).

Pesleşmenin hızı sesin neye dönüşeceği konusunda işaretler verebilmektedir. Hızlı ya da ani bir pesleşme, sesin basa dönüşeceğini, yavaş ve kademeli olan pesleşme ise bir tenora dönüşeceğini gösterdiği gibi bu durum hızlı pesleşen sesin daha kısa bir süre (birkaç aydan bir sömestre değişiklik gösterebilir) alto-tenor aşamasında kalacağını, yavaş pesleşen sesin ise daha uzun bir süre (bir yıldan on sekiz aya hatta daha uzun bir zamana yayılır ve tespit edilmesi zordur) bu aşamada kalacağını gösterir. Sesin kademeli olarak değişmesi alto-tenordan tenor aşamasına geçildiğini tespit etmek açısından zordur ancak; eğer ses küçük oktav do'ya düşerse tenor olarak adlandırılır. Ergen erkek altotenor sinıflandırmasında iken seste meydana gelen pesleşme ilk olarak konuşma sesinde kendini gösterir. Değişen sesin geliştiğini gösteren bu aşamada sadece birkaç nota söylese bile, hemen bas olarak sınıflandırılmalıdır. Alto-tenor ranjının en tiz notaları bu aşamada daha hızlı yok olacak, ancak daha pes olanlar kalacaktır. Ancak, ergen erkek değişmeyen sesindeki en pes notaları söyleyemeyecek; onları değişen sesiyle söyleyecektir. Yaklaşım, değişen sesin ne kadarının pes alto-tenor ranjında kaldığı önemli olmaksızın değişen sesin gelişmesini daima teşvik etmek olmalıdır. (McKenzie, 1956).

Alto-tenor sınıflandırması daha çok yavaş değişen sesler için uygundur. Bu sebeple sesi hızlı değişenler alto-tenor sınıflandırmasında şarkı söylemekte zorlanmaktadır. Bu aşama alto-tenor ranjında tessituranın bir veya iki ton altına düşmesi ile meydana gelmekte olup bu sesler, yaklaşık tessiturası küçük oktav mi ile re ${ }^{1}$ olan bas grubunda sinıflandırılamazlar (McKenzie, 1956).

\section{John M. Cooksey’nin Mutasyon Dönemi Ses Sınıflandırma Yöntemi}

Sınıflandırma için en önemli faktörler; ranj, tessitura, ses kalitesi ve register gelişimidir. Ses kalitesi çok subjektif bir terimdir ve herhangi bir zamanda herhangi bir nota için harmonik bir spektrum içinde üretilen belli harmonik partilerin güçlendirilmesi ile belirlendiği gibi, sesin genel doğası ve rengini belirtir (Cooksey, 1977c). Erkeklerde ses değişim aşamalarına ve yaş gruplarına göre ses ranj ve tessiturası (tst) aşă̆ıdaki şekilde göstermektedir.

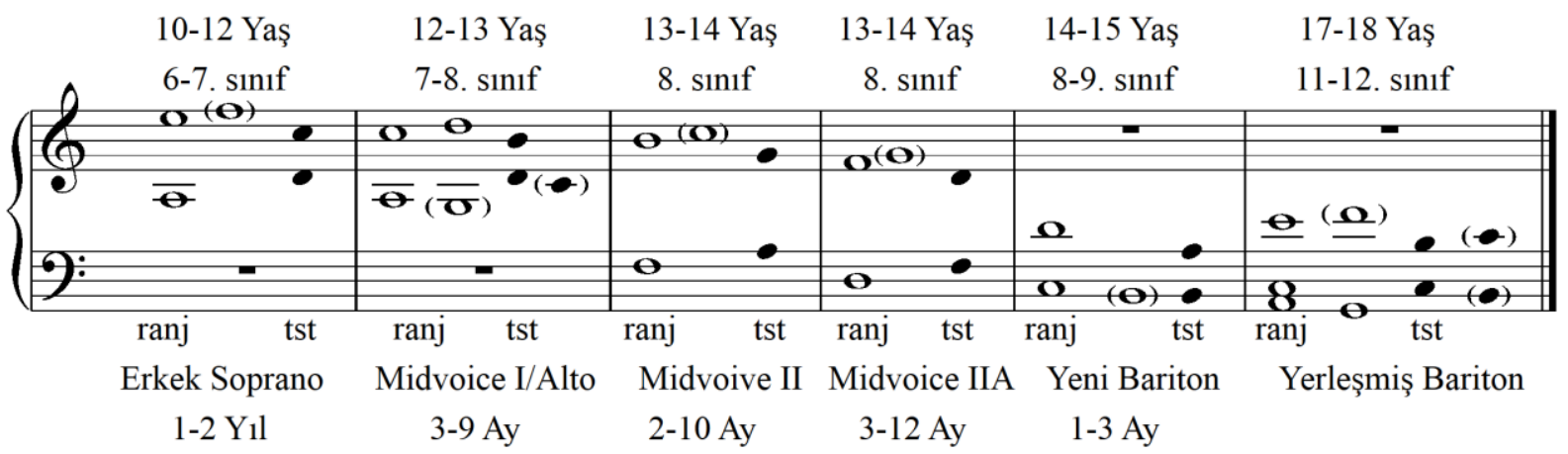


Şekil 5. Erkeklerde Ses Değiş̧im Aşamalarına ve Yaş Gruplarına Göre Ses Ranj ve Tessiturası (Cooksey, J. M. (1977b). The development of a contemporary, eclectic theory for the training and cultivation of the junior high school male changing voice: Part II scientific and empirical findings; some tentative solutions, The Choral Journal, 18(3), 5-16; Cooksey, J. M. (1978). The development of a contemporary, eclectic theory for the training and cultivation of the junior high school male changing voice: Part IV selecting music for the junior high school male changing voice, The Choral Journal, 18(5), 5-18; Cooksey, J. M. and Welch, G. F. (1998). Adolescence, singing development and national curricula design. British Journal of Music Education, 15(1), 99-119. doi:10.1017/ S026505170000379X).

Bir koro şefi on ila on beş dakika vakit ayırarak erkek seslerini mutasyonun aşamalarına göre sınıflandırmak ve ses yeteneklerini keşfetmek için bireysel testler yapmalıdır. İyi düzenlenmiş bir ses testi hazırlandığı taktirde şu faktörleri değerlendirmek mümkündür; Ranj, tessitura, ses kalitesi, register gelişimi, konuşma ses perdesi, postür ve nefes kontrolü, ses yetenekleri, dinamik ritmik ajilite, perde ajilitesi, tonal hafıza, diksiyon, entonasyon, gördüğü şarkıyı söyleme yeteneği, öne çıkan kişilik özellikleri, vokal güçlü ve zayıf yanlar. (Cooksey, 1977c). Bir koro şefi bu faktörlere göre aşağıda açıklanan prosedürü dikkatle uygulamalıdır.

Öğrenciden, müzikal geçmişini sorgulamak amacıyla hazırlanmış olan ses sınav kartını (bu kart onun müzikal geçmişinin ayrıntılarını verir: koro deneyimi, enstrüman dersi, vb.) doldurması istenir. Hem onu rahatlatmak hem de tonları eşleştirmeye nereden başlanacağı konusunda fikir edinilebilmek için öğrenci ile konuşmak gerekir. Eğer ses kulağa pes gelirse ve boğuk bir niteliğe sahipse, küçük oktav Do veya küçük oktav Re Majörde uygun tonda egzersize başlanabilir. Egzersize başlamadan önce dikkat edilmesi gereken birinci husus öğrencinin klavyeyi görmediğinden emin olunmasıdır. Klavyeyi gören öğrenci tiz notaları görüp heyacanlanabilir. Diğer bir husus ise uygun tonu bulmaktır. Uygun tonu bulmak için konuşma sesine yakın bir yerde (genellikle öğrencinin şarkı söyleme alanındaki en pes noktadan yaklaşık 3. ve 4. sırada) başlamak gerekir. Başlangıçta şarkı söylemek için rahat alanlar bulmak önemlidir. Bu güven oluşturur ve ses sınavına olumlu bir başlangıç yapılmasını sağlar. Öğrenciden birkaç perdede açık ünlü bir harf (örneğin: lah) söylemesi istenir. Önerilen başlangıç perdeleri şunlardır:

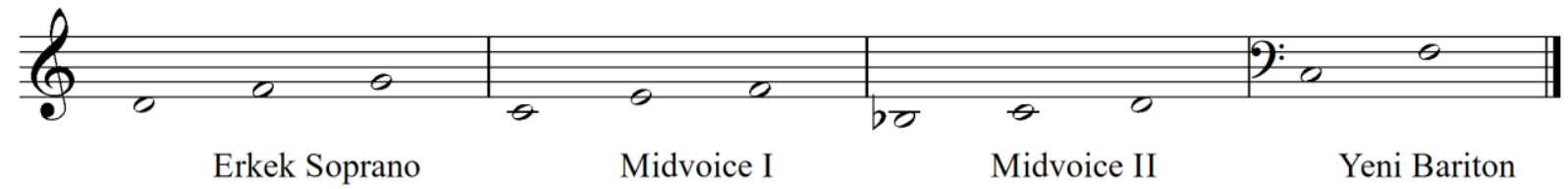

Şekil 6. Uygun Ton Bulmak için Başlangıç Perdeleri (Cooksey, J. M. (1977c). The development of a contemporary, eclectic theory for the training and cultivation ofthe junior high school male changing voice: Part III developing an integrated approach to the care and training of the junior high school male changing voice, The Choral Journal, 18(4), 5-15).

Öğrencinin kendisini rahat ve iyi hissetmesi önemlidir. Sesini enerjik ve güvenli bir şekilde yansıtması için öğrenciyi cesaretlendirmek, hatta başlamasına yardımcı olmak için onunla biraz şarkı söylemek gerekebilir. Pozitif, istekli ve coşkulu olmak önemlidir. Örencinin bütün potansiyelini gösterebilmesi için güven duyması gerekir. Güven verilmediği sürece, öğrenci gerçekten yapabileceklerini doğru bir şekilde aktaramaz. Güven ortamı oluşturulduktan sonra uygun ses perdesi bulunmalıdır. Eğer öğrenci perdeyi rahatça eşleştirirse, ona "mah" hecesi ile 1-2-3-4-3-2-1 (diyatonik skala tonları: $=60$ ) basit bir dört nota okuması söylenir. Şablonun ilk notası üzerinde sadece "M" seslendirilir. Rahat bir şarkı alanında tekrar başlanır ve her seferinde aynı sıralamayı kullanarak yarım adımlarla pesten tize tizden pese inilir ve çıkılır. Bu esnada ranj, tessitura, nefes, destek, vokal kontrol, ses projeksiyonu ve register değişiklikleri için kontrol edilmelidir. Ardından tessitura, diksiyon, vokal problemler, nefes kontrolü, hacim ve tonlamayı kontrol etmek için, öğrenciden "My Country 'Tis of 
Thee" (America) şarkısını söylemesi istenir (Ek 2). Bu şarkıya birçok kişi aşina olduğundan ve sınırlı bir ranja (majör altıl1) sahip olduğundan, bu özellikle başlangıçta ses testi yapmada uygundur. Rahat bir perdede başlamaya dikkat edilmelidir. Önerilen başlangıç perdeleri şunlardır:

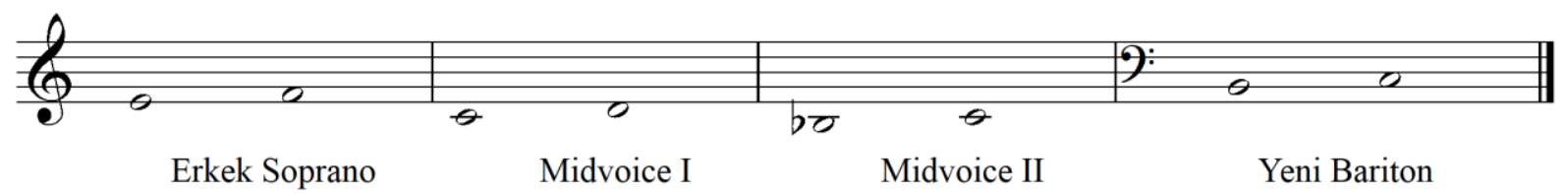

Şekil 7. Uygun Ton Bulmak için Önerilen Başlangıç Perdeleri (Cooksey, J. M. (1977c). The development of a contemporary, eclectic theory for the training and cultivation ofthe junior high school male changing voice: Part III developing an integrated approach to the care and training of the junior high school male changing voice, The Choral Journal, 18 (4), 5-15).

$\mathrm{Bu}$ egzersizler yaptırılırken sesin en rahat yeri dinlenmelidir. Eğer sesin mutasyon aşamasından emin olunamazsa (konuşma sesini dinledikten ve eşleme tonunu uyguladıktan sonra, dört nota egzersizi) yukarda verilen kuralları kullanarak birkaç farklı perde denenmelidir. Daha sonra, bazı hızlı esneklik alıştırmaları denenir ve ayrıca register değişiklikleri kontrol edilir. 1-3-5-1 (örnek desen: do-mi-sol-do) 5-3-1 (örnek desen: sol-mi-do) deseni "pah” hecesi üzerinde sekizlik notalarla ( • = 120) söylenir, aynı diziyi kullanarak yarım adımlarla çıkılır ve inilir (pesten tize tizden pese). Midvoice II'nin bir oktavlık bir alana yayılması zor olacağından. Bunun yerine aşağıdaki alıştırma deseni denenmelidir:

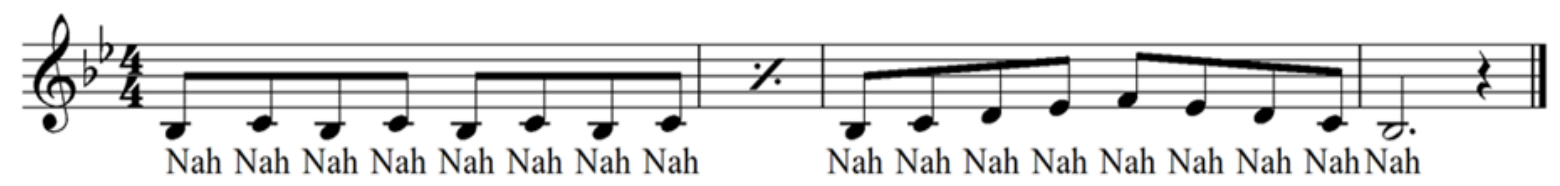

Şekil 8. Midvoice II için Hızlı Esneklik Alıştırması (Cooksey, J. M. (1977c). The development of a contemporary, eclectic theory for the training and cultivation of the junior high school male changing voice: Part III developing an integrated approach to the care and training of the junior high school male changing voice, The Choral Journal, 18(4), 5-15).

Tüm erkekler için başka bir alıştırma: 1-3-5-3-1 $(\bullet=120)$, bariton için küçük oktav do, Midvoice I için do ${ }^{1}$, Midvoice II için küçük oktav si b ve erkek soprano için mi ${ }^{1}$ veya $\mathrm{fa}^{1}{ }^{1}$ de başlanır. Aynı modeli kullanarak çıkılır ve ardından yarım adımlarla inilir. Bu "pah" hecesi üzerinde söylenir. Testin devamında tonal ve ritmik hafıza değerlendirilmelidir. Üç notalı kalıplar adım adım çalınır ve öğrenciden tekrar etmesi istenir. Sonra üçlü için gidilir ve giderek daha geniş çaplı aralıklar için çalışma yapılır. Ardından 4 veya 5 sekansa (sekvense) gidilir. Ör. 1-2-3, 3-2-1, 2-3-4, 4-3-2, 1-3-5, 53-1, 1-4-5, vs. 1-3-5-3-1, 1-2-3-4-5, 1-2-5-4-3, Öğrenci gerçekten iyi ise, değiştirme işaretleri eklenerek çeşitlendirilebilir. Ritmik hafıza için kolaydan zora hazırlanan ritm kalıplarını öğrencinin tekrar etmesi istenir. Bunun için alkış vb. bir yanıtlama tekniği kullanılabilir. Aşağıda birkaç örnek verilmektedir.

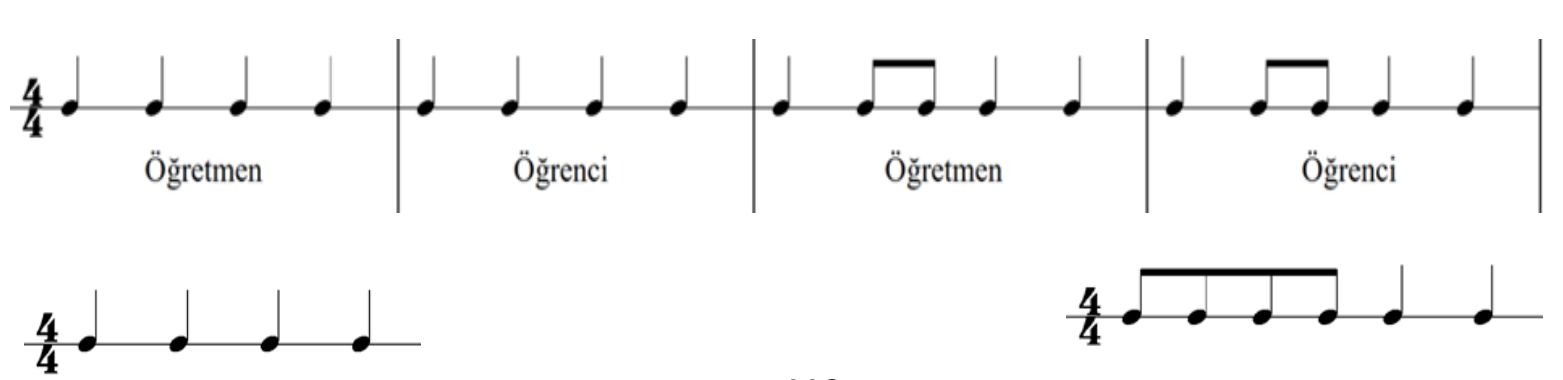



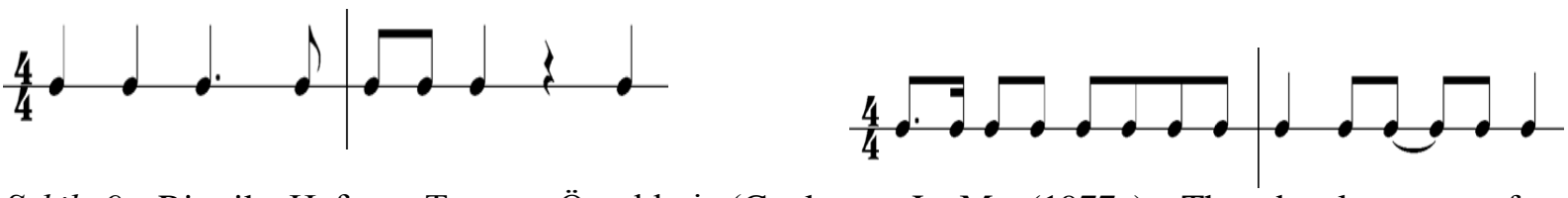

Şekil 9. Ritmik Hafiza, Tempo Örnekleri (Cooksey, J. M. (1977c). The development of a contemporary, eclectic theory for the training and cultivation ofthe junior high school male changing voice: Part III developing an integrated approach to the care and training of the junior high school male changing voice, The Choral Journal, 18(4), 5-15).

Bütün bu aşamaların ardından deşifre şarkı söyleterek ses sınavı yapılabilir. Ortaokuldaki pek çok erkek bunu yeterli bir müzikal geçmişe sahip olmadığından dolayı yapamaz. Tonal ve ritmik egzersizler erkek şarkıcının müzisyenliği hakkında temel bilgiler sağlamaktadır. Eğer öğrencinin iyi bir tonal hafızası ve mükemmel ritmik kontrolü varsa, O koro için gerçek bir varlık olacak ve uygun eğitim verilirse, hızlı bir şekilde müzik okumayı öğrenecektir (Cooksey, 1977c).

Cooksey (1977c) eğer tempo hızlı ise yukarıdaki prosedürleri tamamlamak yönetici için sadece yaklaşık olarak on ila on beş dakika sürmeli ve test edilecek kriterler her öğrenci için bir ses sınavı kartında listelenmelidir. Bir sonraki test daha az detaylı olabilir. Özellikle öğrenci 8. sınıftaysa ve sesi Midvoice II sınıflandırmasına girmişse, ranj/ tessitura değişiklikleri kontrol edilmelidir. Her bir öğrenci için ayırılacak yeterli zaman bulunmaması durumunda grup testi yapılması gerekebilir. Böyle bir durumda sesler kendi partilerine çok hızlı bir şekilde yerleştirilmelidir.

Karma bir koro için 8-9. sınıf iki gruba ayrılır, erkekler odanın bir tarafında, kızlar diğer tarafindadır. Herkesten Do Majör tonunda “Amerika” yı söylemeleri istenir (Ek 2). Do Majördeki 6’lı Majör dizi, tüm partiler için makul vokal ranja uyar. Baritonlar iki kat daha pes oktavdayken, ortaokul kızları, midvoice I ve II'ler sol anahtarı ses alanı içinde şarkı söyler. Başka bir "sınırlı ranj”da şarkı kullanılmak istendiğinde, şarkının küçük oktav si b'den sol ${ }^{1}$ veya $1 a^{1}$ e kadar olan ses sınırını aşmadığından emin olmak gerekir. Erkek çocuklardan Do Majörde şarkı söylemeleri istenir. Do ${ }^{1}$ altındaki oktavda şark1 söyleme sesleri dinlenir. Öğrencilerin etrafında dolaşarak, alt oktavda şarkı söyleyen bölümdeki erkeklere işaret edilerek şarkı söylemeyi kesmeleri istenir. Bu sesler baritondur. Kalan çocukların (baritonlar bölüm olarak bir araya getirildikten sonra) "Amerika" şarkısını fa ${ }^{1}$ veya sol $^{1}$ üzerinde söylemeleri istenir. Bölüm boyunca yürünür ve üst oktavda şarkı söyleyenlere işaret edilir. Bunlar değişmemiş erkek çocuk sopranolar ya da muhtemelen midvoice I'lerdir. Bu sesler tiz bir partiye (tercihen sosyal nedenlerden dolayı alto) yerleştirilmelidir. Çocuklar 8. sinıfta çok bilinçlidir ve karma bir koroda soprano partisi ile "tanımlanmak" istememektedir. Bu sebeple, öğretmen bu sesleri tenora vermek isteyebilir, gerçekte elbette ki bu bölüm zamanının çok pes bir partisi olacaktır. Her durumda, erkekler erkek bölümünün geri kalanına yerleştirilmelidir. Erkek sopranoları (değişmemiş ses) $\mathrm{fa}^{1}$ veya sol ${ }^{1}$ 'de "Amerika" şarkısında doğruladıktan sonra kalanlar Midvoice II olarak sınıflandırılır. Onlardan küçük oktav si b’ de “Amerika” şarkısını söylemeleri istenir ve daha sonra onlar tenor bölümüne verilirler. Testin devamında kızlardan, Sol Majör'de “Amerika” şarkısını söylemeleri istenir. "Amerika” şarkısını do ${ }^{1}$ veya küçük oktav si b'de söylemeleri istenir ve en güçlü, en gelişmiş sesler seçilir. Hem üst hem de alt registerlerde güçlü olan sesler alto ve soprano arasında eşit olarak bölünebilir (Cooksey, 1977c).

Yukarıdaki prosedür erkek çok sesli korolarında bütün ses tip ve aşamaları için (bariton I-II, tenor I-II, midvoice I-II) aynı ilkeler uygulanarak gerçekleştirilmelidir. İki ve üç partili müzik için varyasyonlar ortaya çıkacaktır. Ana fikir, değişmeyen (erkek sopranolar), değişen (orta ve ikincisi) ve yeni değişmiş (bariton) sesleri birbirinden ayırmak ve böylece birleşik bölümlerin hemen 
kurulabilmesidir. Bu, koro şefine seçtiği herhangi bir müziği öğretmede çok esneklik sağlar. Aynı zamanda genç şarkıcılara kendi şarkı seslerinin yetenekleri ve sınırlamaları hakkında bilgi edinmeye başladıklarında heyecan ve güven aşılar (Cooksey, 1977c).

\section{Lynne Gackle’ın Mutasyon Dönemi Ses Sınıflandırma Yöntemi}

Bir müzik öğretmeni, ergenlik çağındaki fizyolojik değişimlerden geçerken öğrencilerinin ses sağlı̆̆1 ve gelişimine karşı büyük ve ciddi bir sorumluluğa sahiptir. Vokal gelişim sırasında fizyolojik değişikliklerin gerçekleştiği zaman, genç bir kızın hayatındaki en kırılgan noktalardan biridir. Vokal enstrümanı öğretmenin cehaleti nedeniyle yanlış yönlendirilir veya yanlış sınıflandırılırsa, bir yetenek kaybedilebilir, boşa harcanabilir, hasar görebilir veya en azından potansiyeli kısmen kullanılabilir. Her eğitimci, değişen ergen kızın sesi üzerine mevcut araştırmaları incelemeli, kendini eğitmek için zaman ayırmalıdır. Bir müzik öğretmeni sadece notalar ve ritimler öğretmekle kalmamalı, aynı zamanda öğrencilerine kendi benzersiz, dayanıklı enstrümanlarına sahip olmalarını sağlamak için onlara vokal teknik ve sağlık konusunda talimat verebilmelidir. (Haston, 2007). Ergenlik çağı bu anlamda oldukça önemlidir. Bu dönemde erkeklerde, sesin koyulaşmaya başlamasıyla birlikte doğal oluşumlar ortaya çıkar ve ses mezzo-soprano, alto ve bazı durumlarda da tenor niteliğinde özellikler gösterir. Kızlarda ise ses tipik olarak soprano olmasına rağmen uygunsuz bir sınıflanadırma yoluyla sese zarar vermemek için vokal gelişim takip edilmelidir. Genellikle on iki yaş civarındaki alto olarak sınıflandırılan kızlar bu regiterde iyi okumaları veya aniden tiz registerde şarkı söylemekte zorlanmaları ve göğüs sesinde şarkı söylemek için daha az çaba harcamaları nedeniyle alto aralığında söyleyebilirler. Ancak bu çağda sadece alto aralığında şarkı söylemek, ses tellerine zarar verebileceği gibi toplam ses ranjınıda dramatik olarak azaltabilir (Gackle, 1985).

Ses değişimi döneminde bütün kızların seslerinin soprano olarak sınıflandırılması gerektiğini ve kızlarda alto olarak sınıflandırılabilecek bir sese rastlamanın zor olduğunu belirten Gackle (1985; 1991; 2006) bu dönemdeki kızların seslerini (bireysel farklılıklar olmakla birlikte) yaşa, mestrual özelliklere ve sesin özelliklerine (ortalama konuşma perdesi, vokal ranj, tessitura, register gelişimi, genel ses kalitesi/timbre) göre aşağıdaki prosedürü kullanarak değerlendirmekte ve siniflandirmaktadir.

Ortalama Konuşma Perdesi: Öğrencilerden 10'dan geriye saymaları istenir. Bu esnada rakamlar arasında kesinti ve duraklama olmaması sürekli bir hava akışı içinde konuşulması sağlanmalıdır. Dikkatli bir şekilde dinlenerek klavyede duyulan ortalama perde eşleştirilir (Gackle, 2006).

Vokal Ranj: Konuşma perdesinin hemen üzerinden başlayarak, öğrencinin "a" vokalini seslendirmesi sağlanır. Öğrenciden aşağı ranja doğru 5 nota (sol-fa-mi-re-do) seslendirmesi istenir ve egzersiz sürekli alt ranja doğru hareket etmelidir. Tını değiştiğinde veya tonda gerginlik meydana geldiğinde dikkat etmek gerekir. Öğrencinin üretebildiği en düşük şarkı perdesi not edilir. Başlangıç perdesine geri dönülür ve üst ranja doğru ilerleyerek aynı işlem tekrar edilir. Üretebildiği en son perde en üst şarkı perdesi olarak not edilir. Öğrencinin ses genişliği tespit edilmiş olur (Ses aralığının doğru bir şekilde tespit edilebilmesi için öğrencilerin cesaretlendirilmeye ihtiyaçları vardır. Kendilerini rahat hissetmeleri ve güven duymaları oldukça önemlidir. Bu güven oluştuktan sonra; çeneyi gevşeterek ağzı daha fazla açması, daha fazla nefes desteği kullanması, gerilimi ortadan kaldırmak için birkaç "siren" sesi örneği verilebilir. Ayrıca sesi serbest bırakmak için devinişsel hareketler yaptırılabilir; elleri ve kolları kullanarak dairesel hareketler vb.) (Gackle, 2006).

Tessitura (Rahat Şarkı Aralığı): Bir "a" vokali kullanılarak, öğrencinin ses ranjı içindeki belirli bir notada kreşendo yapması sağlanarak en iyi renk, üretim kolaylığ 1 , netlik vb. için ses dinlenir. Öğrenciden Amerika gibi tanıdık bir şarkıyı çeşitli tonlarda (Fa majör, A majör, D majör) söylemesi 
istenir. En iyi üretim, netlik ve hacim kolaylığının oluştuğu notaların genişliğine dikkat edilir (Gackle, 2006).

Register Gelişimi: Ses gelişmeye başladığında, register değişiklikleri (yeniden ayarlamalar) gözlemlenebilir. En bariz ilk geçiş notası genellikle $\mathrm{fa}^{1}-\mathrm{la}^{1}$ aralığında bulunur. $\mathrm{Bu}$ oluşumu gözlemlemek için: öğrencinin, küçük oktav la'dan başlanarak yukarı doğru majör tonlarda şark1 söylemesi sağlanır. Belirtilen aralıklarda tını farklılıkları dikkatli bir biçimde dinlenir. Bu fark genellikle belirli bir notada duyulacak ve sonraki nota yeni registerde duyulacaktır (öğrencilerin ergenlik döneminde ses veya koro eğitimi almaları ses gelişiminin kolaylaşmasına ve ton üretiminin iyileşmesine yardımcı olabileceğinden bu farklılı̆g algılamak bu öğrencilerde zordur). Ses olgunlaşmaya devam ettikçe, register geçişleri daha belirgin hale gelir ve geçiş notası $\mathrm{re}^{2}$-fa ${ }^{\# 2} \mathrm{de}$ (yetişkin soprano sesinde bulunan geçişe yaklaşarak) görülür (Gackle, 2006).

Ses Kalitesi: Genel olarak, ses kalitesi gözlemlenmesi en kolay kriterdir. Ortaokul sesleriyle çalişanlar için, soluklu ve boğuk bir ses kalitesi genellikle mutasyon dönemiyle ilişkilidir. Gelişim evrelerine dayalı ses sınıflandırmasını belirlerken ve flüt benzeri çocuk sesten nefesli/havalı mutasyon aşamalarına doğru ilerlerken ergen kızın sesinde oluşan ince farklılıkları ayırt etme becerisi oldukça önemlidir. Ses değişiminin yüksek noktasında, bu nefeslilik daha barizken genç yetişkin aşamasına doğru nefeslilik azalmaya eğilimlidir ve bunun sonucunda ortaya çıkan tınıda daha fazla netlik ve rezonans vardır (Gackle, 2006). Menstruayonun aşamaları, yaş ve sesin özelliklerine göre ergen kızların sesleri aşağıdaki şekilde sınıflandırılabilir.

Aşama I (Pre-pubertal Evre 8-10 (11) Yaş): Berrak bir kafa sesi ve flüt benzeri bir kalitededir (8-10 yaşlarında, kızlar ve erkekler neredeyse aynı ses rengine ve kalitesine sahip olma eğilimindedir) (Gackle, 1985; 1991).

Aşama IIA (Pre-Menarcheal Evre 11-12 (13) Yaş): Olgunlaşmanın ilk bulguları fiziksel ve anatomik değişikliklerin ortaya çıkması ile başlar. Mutasyonel chink (aritenoid kıkırdağı tarafından bağlanan ses tellerinin arka uçlarının kapanmaması sonucu oluşan üçgen boşluk) nedeniyle ses nefesli olma eğilimi gösterir. Fonasyon, registerler arasında yetersiz olmaya başlar $\left(\mathrm{re}^{1}\right.$ ile $\mathrm{fa}^{1}$ arasındaki geçişte ve $\mathrm{fa}^{2} \mathrm{ve} \mathrm{sol}^{2}$ nin etrafindaki geçişte). Bu düzeydeki belirtiler arasında: şarkı söylemede zorluk, orta ve tiz ranjda nefesli ses, alt ranjda dolgun bir ton görülmekle birlikte alt registerden üst registere geçişte çocuksu sese geri dönüş görülür (Gackle, 1985; 1991).

Aşama IIB (Post-Menarcheal Evre 13-14 (15) Yaş) Ses Özellikleri: Çok kritik bir dönemdir, ses aralığı yukarı ya da aşağı hareket edebilir ya da her iki taraftan da daralabilir, bu sebeple altı ya da yedi nota aralığında rahat şarkı söylemek daha verimlidir. Register kırılmaları sol $^{1}$-si ${ }^{1}$ arasında ve $\mathrm{re}^{2}-\mathrm{fa}^{\# 2}$ arasında görülür. Pes notalarda daha kolay ses üretilebildiğinden alto kalitesinde bir yanılsama meydana gelebilir. Bu kolaylık sebebi ile sürekli alt ranjda şarkı söyleme eğilimi sese zarar verebilir. Sesin gelişimi ile ilgili en ön görülemez dönem olduğundan, ergen kızlar dört ila altı aylık aralıklarla değerlendirmeye tabi tutulmalıdır. Karakteristik sorunun belirtileri arasında: herhangi bir üst solunum yolu enfeksiyonu olmamasına rağmen boğaz ağrısı hissetme ve ses kısıklığı, ses çatlaması, temel olarak şarkı söylemenin zorlaşması, en minimal şarkı söylemeden sonra ses kısıklığ1 ortaya çıkması ve gerçek hacim elde etme yeteneği yokluğuyla birlikte tonun net olmaması eğilimi vardır (Gackle, 1985; 1991).

Aşama III (Genç Yetişkin Kadın/ Post- Menarcheal Evre 14-15 (16) Yaş): Ses olgunlaştıkça ton daha dolgunlaşır ve zenginleşir. Mutasyonel chink azalmaya, sesteki açıklık/berraklık geri gelmeye, şarkı söylemek kolay görünmeye başlar. Kalite hâlâ tam ve dolgun değildir, ancak oldukça açık ve berraktır, nefessizlik açıktır. Bu aşamada sesi, her zaman olduğu gibi, mümkün olduğunca esnek tutmak önemlidir. Aralık yukarı ve aşağı her iki yönde de çalışmalıdır. 14 yaşına kadar ya da 16 yaşına kadar geçen sürede, kontrolsüz olsada, vibrato sesin içine girmeye başlar. Ses ranjında artış olmakla birlikte sesin rezonans ve ajilitesi de artar. Yetişkin sesine yaklaşmaya başlayan seste register kırılmaları da benzer özellik göstererek ve $\mathrm{re}^{2}-\mathrm{fa}^{\# 2}$ aralığında daha belirginleşir. (Gackle, 1985; 1991). 


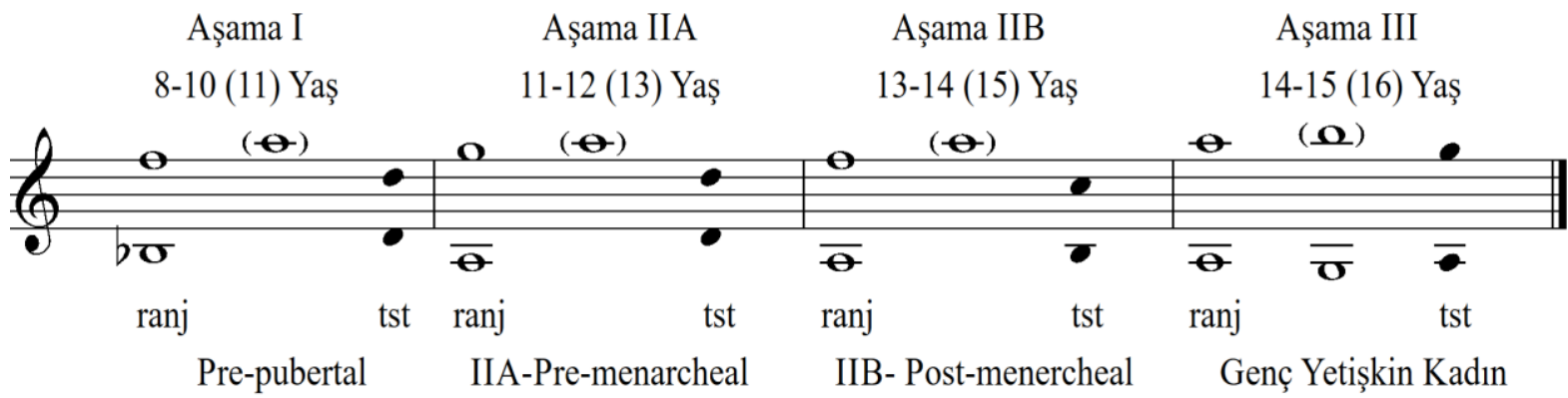

Şekil 10. 8-16 Yaş Aralığında Bulunan Kızlarda Ses Ranj ve Tessiturası (Gackle, L. H. (1985). The young adolescet female voice (ages 11-15): classification, placement, and development of tone, The Choral Journal, 25 (8), pp. 15-18.; (Gackle, L. (1991). The adolescent female voice: Characteristics of change and stage of development, Choral Journal, 31 (8), 17-25).

\section{Don L. Collins’in Mutasyon Dönemi Ses Sınıflandırma Yöntemi}

Ses değişim süreci benzer özellikler taşımakla birlikte bireye özgüdür ve her bir birey bunu farklı oranlarda ve sürelerde tamamlayabilir. Değişimin ikinci evresinde ergen erkekler için eser seçerken, toplam ranj1 yaklaşık olarak büyük oktav si $b$ ile $\mathrm{fa}^{1}$ arasındaki bariton partisini kapsamalıdır. Bu alan en tiz ve en pes notaların maksimum genişliğidir. Çoğu erkek küçük oktav re ile $\mathrm{re}^{1}$ arasında çok daha rahat şarkı söyler. Değişimin ikinci aşamasındaki erkekler için parti do ${ }^{1}$ üzerinde hareket ettiği zaman bu perdeleri üretemeyen erkeklere özel yazılmış müzik partileri opsiyonel notalar içermelidir. Bunun tersine, parti küçük oktav fa'nın altında hareket ettiğinde henüz pes tonları oluşmamış parlak baritonlar için notalar opsiyonel olmalıdır. Müzik eğitmenlerinin en büyük yanılgısı do ${ }^{1}$ 'den küçük oktav fa' ya kadar çok dar bir ranjda olan açık renkli baritonları cambiata olarak sınıflandırmaktır. Dar aralıklı bu çocuk kesinlikle değişimin ikinci aşamasındadır ve henüz alt tonları üretemese de bariton veya tenor bölümüne verilmelidir. Onu bir cambiata olarak sinıflandırmak, özellikle kafa sesini (gelişmekte olan falsetto) nasıl kullanacağını bilmezse çok uygun olmayacaktır. Çünkü cambiata parçasının üst tonlarını üretmeye çalışmak büyük bir gerginlik yaratacak, bu ise tonun sert/tiz ve gergin olmasına neden olacaktır. Değişime devam eden sesi teşvik etmek için onu bariton veya tenor bölümüne yerleştirmek çok daha avantajlıdır. Çünkü sesin alt tonları kullanıldıkça daha da güçlenecek, kullanım ile çok kısa sürede yeni alt tonlar eklenecek ve kısa bir süre içinde bariton veya tenor bölümünün tam ses genişliğinde şark1 söylenebilecektir (Collins, 1987).

Koroda şark1 söyleyen bir erkek çocuğunun sesinin değişmesiyle birlikte hangi partide söyleyeceğine karar vermek önem arz etmektedir. Başka bir partiye geçme zamanının gelip gelmediğine karar verirken kullanılması gereken genel kural değişimi her zaman teşvik etmek gerektiğidir. Bir erkek şarkıcı, şarkı söylediği partide belirtilen tonları üretmekte zorlanırken, hemen o parçanın tüm tonlarını üretemeyebilecek olsa bile o bir sonraki partiye taşınmalıdır. $\mathrm{Bu}$ ilkenin uygulanmasının çok zor olduğu zamanlar vardır. Bir koro grubundaki cambiata bölümünün büyük kısmı aniden parçanın tiz notalarında güçlük çekmeye başlarsa, genellikle onları hemen bariton kısmına taşımak gerekir, ancak eğer yaklaşan bir performans var ise korodaki dengeyi bozmamak adına bu erkekler değişim yapabilecekleri zamana kadar cambiata şarkı söylemeye devam etmelidirler. Ayrıca üst perdelerin üretimi gerginlik ve zorluk yarattığı zaman, kafa sesini (veya falsetto) kullanmaya teşvik etmek hayati derecede önemlidir. Koro şefi, kafa sesi (falsetto) kullanmanın gerekliliği konusunda kararlı olmalıdır. Ergen erkek, sesin volüm gücünün büyük ölçüde kısıtlandığından şikâyet edebilir. Muhtemelen, büyük bir çaba sarf etmesine rağmen, tonları şiddetle vurma eğilimi gösterecektir. Bu aşamada birçok uygunsuz üretim alışkanlığı kazanılır ve gelecek yıllar boyunca bu onun aklından çıkmayacaktır. Mümkünse, onu alt partiye taşımak ve mutasyon sürecini teşvik etmek gerekir. İlerleyen yıllarda daha özgür, daha rahat ve daha kolay şarkı söyleyecektir. Bütün bu sebeplerden dolayı özellikle de her gün şarkı söyleyen erkekler dikkatli bir şekilde izlenmelidir (Collins, 1987). 
Eğer öğretmen Soprano-Alto-Tenor-Bas (SATB) müziği kullanılıyorsa, cambiatanın ihtiyaçlarına cevap verecek olanı seçmeye dikkat etmelidir. Alto ya da tenor bölümünde, cambiatanın başarılı olması için önerilen, küçük oktav la-la ${ }^{1}$ ranjını geçen yerler varsa, öğretmen parçayı düzenlemelidir, böylece öğrenci şarkı söylerken başarılı olacaktır. Değişimin ikinci aşamasında erkekler (ergen baritonlar) dikkatlice değerlendirilmelidir. Bunların geniş bir aralıkta üst kısımlarını kullanmalarını gerektiren bir tenor parçasına yerleştirmek, vokal enstrümanın gerginliği ve yanlış kullanımıyla sonuçlanacaktır. Genellikle bas parçası rahat şarkı söylemek için çok pestir. Burada yine, eğer SATB müziği kullanılıyorsa, öğretmen ergen baritonların küçük oktav re-re ${ }^{1}$ aralığında rahat şarkı söyleyeceği parti her ne ise onu düzenlemek için zaman ayırmalıdır. Eğer daha fazla kız ve daha az erkek varsa, lisede ses değişimindeki gruplar için Soprano-Soprano-Cambiata-Bas (SSCB) müziği kullanımı gitgide kabul gören bir uygulamadır. Muhtemelen sadece birkaç cambiata olacağı için, dengeyi korumak için cambiata kısmına lise altosunu yerleştirmek (gerçekte zor bulunur) oldukça kabul edilebilir. $\mathrm{Bu}$, diğer parçalarda tiz sesin kullanılmasına izin verilmesi şartıyla, genç kadın şarkıcı için zararlı değildir. Küçük oktav la ile la ${ }^{1}$ ranjı, SATB müziğindeki birçok alto partisinin kullanıldığ1 alan olması sebebiyle benzerlik gösterir. Şark1 söyleyen ergen erkeklerin psikolojik iyi oluşu için cambiata olarak bahsetmeye devam etmek önemlidir. Kızların geri kalanı birinci ve ikinci sopranolara bölünür ve birkaç istisna dışında değişimin ikinci aşamasındaki tüm erkekler (ergen baritonlar) ve değişen sesler (lise tenorları ve baslar) küçük oktav re ile re $^{1}$ arasında kalan bariton kısmını söyleyeceklerdir. $\mathrm{Bu}$ ses prosedürü, ergen baritona özellikle iyi gelir çünkü çok tiz olabilecek bir tenora veya çok pes olabilecek bir bas parçasına konulmaz. Değişen ses grupları için lisede SSCB vokal sınıflandırması kullanılarak ve kızların üstünlüğü olan grupların müziği SATB veya SopranoAlto-Bas (SAB) sesinden çok daha tatmin edici bir dengeye sahip dört bölümlük şarkıya olanak sağlar, ancak en önemlisi grupta değişen seslerin ihtiyaçlarına cevap verir (Collins, 1987).

\section{Sonuç, Tartıșma ve Öneriler}

Mutasyon dönemi genellikle ortaokul 7. sınıfın sonlarında başlar ve evrelerin süresi, süreci gibi faktörlerin kişiden kişiye değişiklik göstermesi ile müzik öğretmenlerinin daha fazla dikkat ve özen göstermesini gerektirir. Çalışmada mutasyon dönemindeki seslerinin sınıflandırılması konusunda 5'i erkekler 1'i kızlar için olmak üzere dikkat çeken altı yöntem incelenmiştir. Bu yöntemlerin bazı noktalarda birbirinden ayrıldığı, bazı noktalarda birleştiği görülmüştür. Öğrencilerin bu döneme girmeden önce seslerinde görülen belirtileri dikkate almak önemlidir. Öne çıkan özelliklerden biri değişime yaklaşan erkek çocuğun sesinin alışılıışın dışında kalite, parlaklık ve güzellik kazandığıdır. Kizlarda ise; boğaz ağrısı, sesin nefesli olmaya başlaması ve şarkı söyleme performansından sonra ses kısıklığı meydana gelmesidir. Bu aşamada öğrenciler dikkatle gözlenmelidir.

İncelenen çalışmalarda seslerin farklı isimlerle ve belli oranda da farklı ranjlarda sınıflandırıldığı görülmektedir. Shawe (1916) sesleri; soprano I, soprano II, alto I, alto II ve bas olarak, Cooper (1950) soprano, cambiata, bariton ve bas (nadir olarak bulunur) olarak, McKenzie (1956) soprano I, soprano II, alto ve alto-tenor olarak, Cooksey (1977b; 1977c; 1978); soprano, midvoice I/alto, midvoice II, midvoice IIA, yeni bariton ve yerleşmiş bariton olarak, Collins (1987) soprano, cambiata ve bariton olarak sınıflandırmışlardır. Gackle $(1985 ; 1991)$ ergen kızların seslerini; pre-pubertal, pre-menarcheal, post-menarcheal ve genç yetişkin kadın sesi olarak sınıflandırmıştır.

Shawe'in; tessitura ve ses rengini temel aldığı ve sesleri bireysel bir test yöntemi kullanarak sınıflandırdığı, Cooper'ın; ses ranjını temel aldığı ve grup testi yöntemi kullanarak sesleri sınıflandırdı̆̆ , McKenzie'nin; ranj, tını, yaş ve psikolojik faktörleri temel alan bireysel ve grup testi yöntemi kullanarak sesleri sınıflandırdığı, Cooksey'nin ranj, tessitura, ses kalitesi ve register gelişimini temel aldığı bireysel ve grup testi yöntemi kullanarak sesleri sınıflandırıdığı, Gackle'ın; ortalama konuşma perdesi, ranj, tessitura, register gelişimi ve ses kalitesini temel aldığ 1 ve menstruasyonun aşamaları ve yaş ile ilişkilendirerek sesleri bireysel olarak değerlendirdiği ve sinıflandırdığı görülmüştür.

Sınıflandırma yöntemleri incelendiğinde ses ranjının verildiği, ancak tessituranın bazılarında verildiği dikkat çekmektedir. Yöntemlerdeki sınıflandırma ve ranj benzerlikleri aşağıda yer alan 
tabloda gruplandırılarak verilmiştir. Küçük oktav için “k”, büyük oktav için "b” kısaltması kullanılmıştır.

Tablo1.

Mutasyon Dönemi Erkeklerde Ses Sınıflandırma ve Ranjlarının Yöntemler Arasındaki Benzerlikleri

\begin{tabular}{|c|c|c|c|c|c|}
\hline 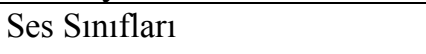 & Shawe & Cooper & McKenzie & Cooksey & Collins \\
\hline $\begin{array}{l}\text { Soprano I/Soprano/Erkek } \\
\text { Soprano }\end{array}$ & $\begin{array}{l}\mathrm{do}^{1}(\mathrm{k} . \mathrm{si} b)- \\
\mathrm{sol}^{2}\end{array}$ & k. si $b-\mathrm{fa}^{2}$ & $\begin{array}{l}\mathrm{do}^{1}(\mathrm{k} . \mathrm{si} b)- \\
\operatorname{sol}^{2}(\mathrm{si} \mathrm{b})\end{array}$ & k. la-mi $i^{2}\left(\mathrm{fa}^{2}\right)$ & \\
\hline Soprano II/Midvoice I-Alto & k. si-re ${ }^{2}$ & & k. si-mi ${ }^{2}$ & $\begin{array}{l}\text { k. la }(\mathrm{k} . \mathrm{sol})-\mathrm{do}^{2} \\
\left(\mathrm{re}^{2}\right)\end{array}$ & \\
\hline $\begin{array}{l}\text { Alto I/ Cambiata } \\
\text { Alto/Midvoice II }\end{array}$ & $\begin{array}{l}\text { k. sol-re }{ }^{2}(\mathrm{mi} \\
\left.\mathrm{b}^{2}\right)\end{array}$ & k. fa-do ${ }^{2}$ & k. la-do ${ }^{2}$ & k. fa-si ${ }^{1}\left(\mathrm{do}^{2}\right)$ & \\
\hline $\begin{array}{l}\text { Alto II/ Alto-Tenor/Midvoice } \\
\text { IIA }\end{array}$ & k. mi-sol ${ }^{1}\left(\mathrm{la}^{1}\right)$ & & k. sol-sol ${ }^{1}\left(\mathrm{la}^{1}\right)$ & k. re-fa ${ }^{1}\left(\operatorname{sol}^{1}\right)$ & \\
\hline Bariton/Yeni Bariton & & b. si b-fa ${ }^{1}$ & & k. do (b. si)-re ${ }^{1}$ & $\begin{array}{l}\text { b. si b- } \\
\mathrm{fa}^{1}\end{array}$ \\
\hline Yerleşmiş Bariton & & & & $\begin{array}{l}\text { b. la }(\mathrm{k} . \mathrm{do} / \mathrm{b} . \\
\text { sol)- } \mathrm{mi}^{1}\left(\mathrm{fa}^{1}\right)\end{array}$ & \\
\hline Bas & b. sol-k. si & b. fa-do ${ }^{1}$ & & & \\
\hline
\end{tabular}

Yöntemlerin benzer özellikleri incelendiğinde; soprano I, soprano ve erkek soprano seslerinin büyük ölçüde örtüştüğü, soprano II ses ranjlarının midvoice I ses ranjı ile büyük oranda örtüştüğü, alto I, alto, midvoice II ve cambiata ses ranjlarının büyük ölçüde örtüştüğü, alto II, alto-tenor ve midvoice IIA ses ranjlarının büyük ölçüde örtüştüğü, bariton ses ranjlarının birbirine yakın olduğu, bas ses ranjlarının büyük ölçüde örtüştügü görülmektedir.

Swanson (1984) sınıflandırma yaklaşımlarına bazı noktalarda eleştiri getirmektedir; her sesin kademeli bir şekilde düşmediğini, bazı seslerin altı hafta içinde iki oktav kadar düşebildiğini, bu seslerin bazılarında tiz sesler işlevselken bazılarında birkaç derin bas tonunun işlevsel olabildiğini, en beklenmedik olanın ise bazı ergen erkeklerin hiç ses üretemediği bir sessizlik alanı olabildiği ancak aynı seslerin pes (bas) ranjda ve tiz ranjda şarkı söyleyebildiğini, bazı seslerin ise tizden pese yaklaşık üç oktavlık bir alanda şarkı söyleyebildiğini belirtmektedir. Diğer bir eleştirisi ise genellikle yetersiz şarkıcılar olarak etiketlenen ergen erkeklerin aslında fry register (cızırtı sesi) veya Rus bası olarak bilinen pulse registerde ses üretebildiklerini belirtmiş, kusurlu veya yetersiz olarak etiketlenen bu ergen erkeklerin uygun bir eğitimle seslerinin değerli birer varlığa dönüşebileceğini eklemiştir. $\mathrm{Bu}$ görüşe benzer olarak McKenzie (1956) alto-tenor sınıflandırmasının daha çok yavaş değişen sesler için uygun olduğunu bu sebeple sesi hızlı değişen ergen erkeklerin alto-tenor sınıflandırmasında şarkı söylemekte zorlanbileceğini belirterek bireysel farklılıklara vurgu yapmaktadır.

Doğanyiğit ve Özaydın (2018) çalışmalarında 2016-2017 eğitim-öğretim yılı müzik öğretim programında yer alan eserlerin mutasyon dönemi ses özelliklerine uygun olmadığı sonucuna ulaşmış, sesin alanı dışında zorlanmasının ise ciddi ses sorunlarına yol açabileceği gibi öğrencilerin dersten uzaklaşmalarına da sebep olabileceğini ileri sürmüşlerdir Otacığlu (2017) çalışmasında mutasyon döneminde sesin uygun repertuvar ile ses sınır ve sınıflandırması yapılarak çalıştırılması gerektiğini belirtmiştir. Thurman (1988) vokal organlardaki büyümenin kişiye göre değişmekle birlikte, tüm bireyler açısından öngörülebilir büyüme aşamalarından geçtiğini, bu sebeple mutasyon dönemindeki bireylerin vokal geleceğini elinde tutan müzik öğretmenlerinin bilimsel veriler doğrultusunda 
belirlenmiş özel sınıflandırma metotlarını kullanarak sesleri sınıflandırması gerektiğini belirtmiştir. Alptekin (2018) Güzel Sanatlar ve Spor Liseleri Bireysel Ses Eğitimi dersi dağarcığında yer aşan 13 eseri incelenmiş, eserlerin mutasyon dönemi öğrencilerinin ses sınırlarını aştığını ve ses sınırlarına uygun olmadığını tespit etmiştir. Orton ve Pitts (2019) öğretmenlerin koro yönetimi alanında eğitilirken mutasyon döneminde kız ve erkek çocukların geçirdiği fizyolojik değişiklikler ve şarkı söyleme üzerine olan etkileri konusunda bilgilendirilmeleri ve aynı zamanda uygun repertuvar seçme konusunda öğretmeni destekleyen bir müfredat geliştirilmesi gerektiğini ifade etmektedir. Bu durumun gerçekleşebilmesi için seslerin doğru yöntemler kullanılarak sınıflandırması önem arz etmektedir. Wisenall (1930) ortaokul müzik öğretmenlerinin ses alanında uzman olması, çocuğun ve mutasyon dönemine girmiş ergenlerin seslerinin fizyolojik özelliklerini bilerek doğru bir sınıflandırma yapabilmesi ve onlara uygun eğitim prosedürünü bilmesi gerektiğini ifade etmiştir (aktaran: Freer, 2008). Kızıldeli (2001) çalışmasında müzik öğretmenlerinin mutasyon dönemi hakkında yeterli bilgiye sahip olmadıkları sonucuna ulaşmış, müzik öğretmeni yetiştiren kurumlarda mutasyon dönemindeki çocuklara verilecek eğitime yönelik konulara yer verilmesinin, sesin değişim ve gelişim evrelerine uygun repertuvar oluşturulmasının önemine dikkat çekmiştir.

Vokal organların zarar görmemesi ve mutasyon sürecinin sağlıklı bir şekilde tamamlanması açısından bu özel dönemde seslerin sınıflandırılması önemlidir. Hangi sınıflandırma sistemi benimsenmiş olursa olunsun önemli olan çocuğun en uygun ranj ve tessiturasının belirlenerek psikolojik olarak da kendini iyi hissedeceği bir adlandırma ile sınıflandırılmasıdır. Ayrıca değişimin sürekli teşvik edilmesinin yanı sıra sesi herhangi bir sınıflamaya uymayan ergen erkekler için uygun bir öğretim yaklaşımı da geliştirilmelidir.

\section{Kaynaklar}

Alptekin, Cemre (2018). Türkiye'de Güzel Sanatlar ve Spor Liseleri Şan Dersi, Şarkı Dağarcığının Mutasyon Dönemindeki Çocukların Ses Sağlığına Olan Etkileri, Yüksek Lisans Tezi, Ondokuz Mayıs Üniversitesi Güzel Sanatlar Enstitüsü, Samsun. (My Country Tis of Thee). (ty). https://www.bethsnotesplus.com/2012/09/america-my-country-tis-of-thee.html adresinden 16.05.2020 tarihinde erişilmiştir.

Busch, S. E. (1973). Practical aspects of our arts: some voice classifications and development in young adolescent choir, The Choral Journal, 14 (1), 21-24.

$\begin{array}{llllll}\text { Carry me back to } & & \\ \text { (ty). }\end{array}$ https://www.musicnotes.com/sheetmusic/mtd.asp?ppn=MN0109346 adresinden 16.05.2020 tarihinde erişilmiştir.

Cevanşir, B. ve Gürel, G. (1982). Foniatri: Sesin oluşumu, bozuklukları ve korunmasında temel ilkeler. İstanbul: Sanal Matbaacilık.

Collins, D. (2012). Using repertoire to teach vocal pedagogy in all-male changing voice choirs conversations with six master teachers. Choral Journal, 52(9), 34-41.

Collins, D. L. (1982). The cambiata concept: More than just about changing voices. Choral Journal, 23(5), 5-9.

Collins, D. L. (1987). The changing voice-the high school challenge, The Choral Journal, 28 (3), 1317.

Cooksey, J. M. (1977a). The development of a contemporary, eclectic theory for the training and cultivation of the junior high school male changing voice: Part I: Existing theories, The Choral Journal, 18(2), 5-14. 
Cooksey, J. M. (1977b). The development of a contemporary, eclectic theory for the training and cultivation of the junior high school male changing voice: Part II scientific and empirical findings; some tentative solutions, The Choral Journal, 18 (3), 5-16.

Cooksey, J. M. (1977c). The development of a contemporary, eclectic theory for the training and cultivation ofthe junior high school male changing voice: Part III developing an integrated approach to the care and training of the junior high school male changing voice, The Choral Journal, 18(4), 5-15.

Cooksey, J. M. (1978). The development of a contemporary, eclectic theory for the training and cultivation of the junior high school male changing voice: Part IV selecting music for the junior high school male changing voice, The Choral Journal, 18(5), 5-18.

Cooksey, J. M. and Welch, G. F. (1998). Adolescence, singing development and national curricula design. British Journal of Music Education, 15(1), 99-119. doi:10.1017/ S026505170000379X

Cooper, I. (1950). The high school choral problem, Music Educator Journal, 37(2), 20-21. https://doi.org/10.2307/3387332

Çevik, S. (1999). Koro eğitimi. (2. Bask1). Ankara: Yurtrenkleri Yayınevi.

Denison, C. (2015). A structural model of physiological and psychological effects on adolescent male singing (Doctoral dissertation, University of Miami).

Doğanyiğit, S. ve Özaydın, N. (2018). Müzik ders kitaplarında öğretilen eserlerin ses değişimi dönemi açısından incelenmesi, International Online Journal of Educational Sciences, 10 (4), 321-350.

Elhankızı, A. (2012). Uygulamalı temel müzik bilgileri. Konya: Eğitim Kitabevi.

Friddle, D. (2005). Changing bodies, changing voices. Choral J, 46, 32-47.

Freer, P. K. (2008). Boys' changing voices in the first century of MENC journals. Music Educators Journal, 95(1), 41-47. https://doi.org/10.1177/0027432108321076

Gackle, L. H. (1985). The young adolescet female voice (ages 11-15): Classification, placement, and development of tone, The Choral Journal, 25 (8), 15-18.

Gackle, L. (1991). The adolescent female voice: Characteristics of change and stage of development, Choral Journal, 31 (8), 17-25.

Gackle, L. (2006). Finding Ophelia's voice: The female voice during adolescence. The Choral Journal, 47(5), 28-37.

Gebhardt, R. (2016). The adolescent singing voice in the 21st Century: Vocal health and pedagogy promoting vocal health (Doctoral dissertation, The Ohio State University).

Haston, G. L. (2007). Physiological Changes in the Adolescent Female Voice: $\backslash b$ Applications for Choral Instruction (Doctoral dissertation, University of Tennessee at Chattanooga, Music).

Hall, M. (2009). Teaching the female adolescent to sing: A survey of choral conductors and voice instructors (Doctoral dissertation, McGill University).

Hook, S. (2005). Vocal agility in the male adolescent changing voice (Doctoral dissertation, University of Missouri-Columbia).

Kızıldeli, N. (2001). Mutasyon Döneminde Ses Eğitiminin Önemi. SÜ Sosyal Bilimler Enstitüsü, Yayımlanmamış Yüksek Lisans Tezi, Konya, (s 1), 5. 
Looney, A. A. (2015). A Comprehensive Study of the Male Voice Mutation.

McKenzie, D. (1956). Training the boy's changing voice. New Brunswick, NJ: Rutgers University Press.

Nguyen, A. (2015). How vocal classification affects young singers. (University Honors Theses, Portland State University)

Orton, A., \& Pitts, S. E. (2019). Adolescent perceptions of singing: exploring gendered differences in musical confidence, identity and ambition. Music Education Research, 21(1), 40-51. https://doi.org/10.1080/14613808.2018.1507019

Otacıŏglu, S. (2017). Ergen seslerinde ses değişimi ve eğitimi, MCBÜ Sosyal Bilimler Dergisi, 15(1), 49-64. Doi: 10.18026/cbayarsos.297841

Robertson, N. L. (1970). A study of the significant contributions of urvin cooper to music education on the junior high school level (Master dissertation, Ouachita Baptist University).

Sassi, S. L. (2010). Effects of vocal registration training on the vocal range and perceived comfort of the adolescent male singer (Doctoral dissertation, Rutgers University-Mason Gross School of the Arts).

Shawe, E. M. (1916). Voice testing and classification of voices, Music Supervisors' Journal, 2(4), 2226. https://doi.org/10.2307/3383232

Skelton, K. D. (2007). The child's voice: acloser look at pedagogy and science. Journal of singing, 63(5), 537-544.

Swanson, F. (1984). Changing voices: Don't leave out the boys. Music Educators Journal, 70(5), 4750. https://doi.org/10.2307/3400768

Sweet, B. (2015). The adolescent female changing voice: A phenomenological investigation. Journal of Research in Music Education, 63(1), 70-88. https://doi.org/10.1177/0022429415570755

Stockton, P. (2014). Classifying adolescent male voices. Choral Journal, 55(3), 85-87.

Stockton, P. H. (2015). Irvin Cooper (1900-1971) and the development of the Cambiata concept for adolescent changing voices. Journal of Historical Research in Music Education, 37(1), 75-87. https://doi.org/10.1177/1536600615608353

Thurman, L. (1988). Voice health and choral singing: When voice classifications limit singing ability. The Choral Journal, 28 (10), 25-33.

Thurman, L. (2012). Boys' changing voices: what do we know now?. The Choral Journal, 52(9), 8.

Tomb, K. M. (2012). Growing through change: training the cambiata voice (Doctoral dissertation, Westminster College). 


\section{Extended Abstract}

\section{Introduction}

The mutation or voice change usually begins at the end of the 7th grade of secondary school and particularly affects the performance of the students in music lessons. If the correct approach is not shown, voice change may cause permanent voice damage and even students may get disconnected from music lessons by getting away from singing. Therefore it is necessary to know what are the stages of the mutation and what kind of approach should be showed to the sounds in this period. Because of the more obvious symptoms in male children, studies have mostly focused on this group. However, female children's voices go through the same process.

\section{Method}

This study is a compilation study that is carried out to bring together different approaches about how sounds are classified during the mutation period. The data obtained by a wide literature review were shared in a certain order.

\section{Result, Discussion and Conlusion}

Mezzo soprano, alto and tenor colors of voice appear in mean as the voice starts to deepen during adolescence. While male voice are classified according to these characteristics, girls are more likely to be classified as soprano During thies period and classification is necessary to avoid damage to the sound (Gackle, 1985). While studying with the changing voices of students in secondary schools, various problems are encountered especially in choral works. Teachers have important responsibilities for the solution of choral problems. To classify the children as soprano, cambiata or baritone, they must determine the quality and limit of the voice of male children, organize them by classifying them as groups, harmonize these groups with the voices of female children and choose appropriate songs according to the voice boundaries of the various groups (Cooper, 1950).

The testing and classification of students aged 12 and over in schools is not only a desirable thing in terms of the musicality of the musical pieces, but also a necessity for the protection of vocal organs of male and female children. Therefore male children with a sign of changed or changing voice should be tested (Shawe, 1916). In this test being performed to classify the male voice according to the mutation stages and to explore the voice capabilities, teachers can evaluate the following factors: range, tessitura, voice quality, the development of vocal register, speech pitch, posture and breath control, vocal abilities, dynamic rhythmic agility, pitch agility, tonal memory, diction, intonation, sight singing ability, prominent personality traits, vocal strengths and weaknesses (Cooksey, 1977c).

When male children enter the period of voice change, they should sing with those who are classified as changing voices (cambiata, alto-tenor, tenors or whatever they may be called). All male children in the period of voice change should sing a part suitable in range and tessitura (Busch, 1973). Although it has similar characteristics, the process of voice change is special to each individual who can complete it at different rates and times. In the second stage of the voice change, the total range should cover approximately the baritone party between large octave $\mathrm{b}$ flat and $\mathrm{f} 1$ during choosing pieces for male children. This is the maximum width of the highest and lowest pitched notes. (Collins, 1987). The alto-tenor range is used to describe male children voice becoming low-pitched which contains an octave between small octave $\mathrm{g}$ and $\mathrm{g} 1$. The ability to sing in small octave $\mathrm{f}$ is an indication that the alto-tenor stage is reached (McKenzie, 1956).

The mutation period usually begins at the end of the 7th grade of secondary school. It is important to consider the symptoms seen in students' voice before entering this semester. For example; In the boy whose voice change will begin, the voice acquires an unusual quality, brightness and beauty. In girls, sore throat, hoarseness of voice and hoarseness occur after singing performance. At this stage, students should be carefully observed. Classification of sounds is important in this special period in order to 
prevent damage to the vocal organs and to complete the process in a healthy way. No matter what classification system is adopted, the most appropriate range and tessitura of the child is determined and classified with a naming that will feel good psychologically. In addition, the change should be constantly encouraged, and the student should be subjected to the next classification unless there is an upcoming performance.

During the mutation period, the content of music courses should be arranged carefully; musical pieces should be selected in accordance with the characteristics of the period. Children entering this period should be tested at regular intervals and placed in the most appropriate class in terms of the stage of mutation. This is essential in order to obtain efficiency from the courses and to provide a suitable conditions to students to obtain necessary gains. 


\section{Ekler}

\section{Ek 1. Carry Me Back to Old Virginny}

Söz-Müzik: James A. Bland

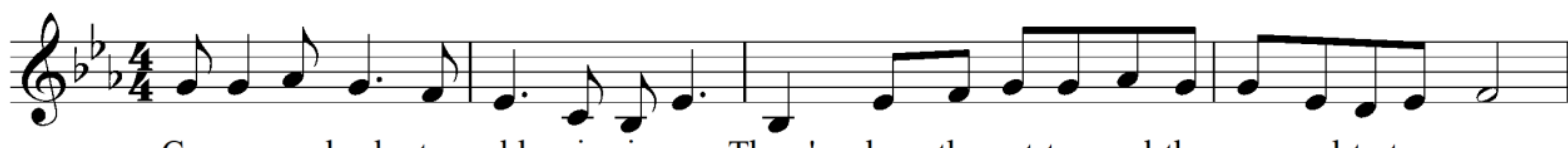

Car ry me back to old vir gin ny There's where the cot ton and the corn and ta ters grow
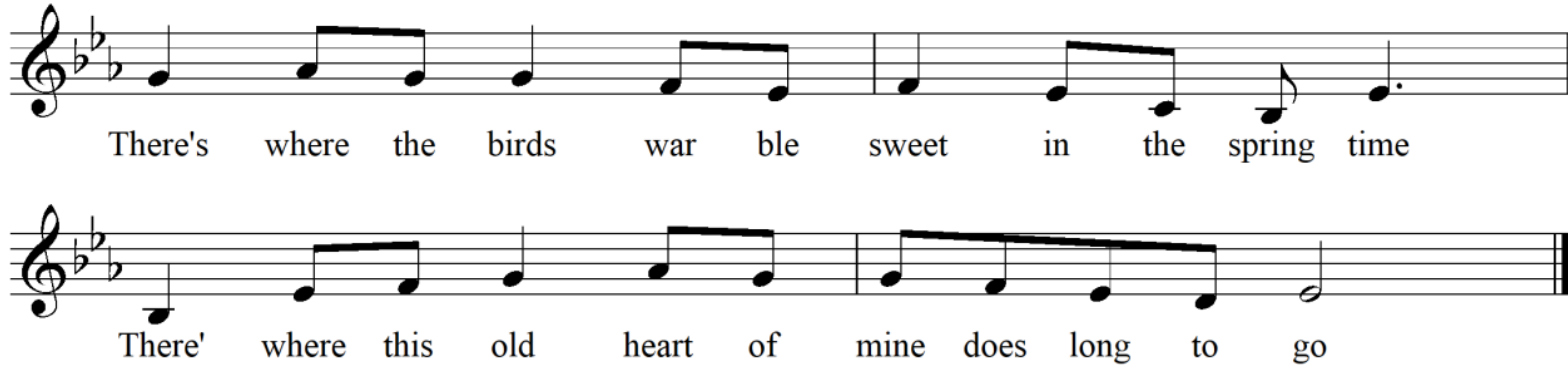

Şekil 12. Mutasyon Döneminde Seslerin Sınıflandırılmasına Yönelik Şarkı Örneği (Carry me back to old virginny. (ty). https://www.musicnotes.com/sheetmusic/mtd.asp?ppn=MN0109346 adresinden 16.05.2020 tarihinde erişilmiştir).

\section{Ek 2. America (My Country Tis of Thee)}

\section{Söz-Müzik: Samuel Francis Smith-Anonim}
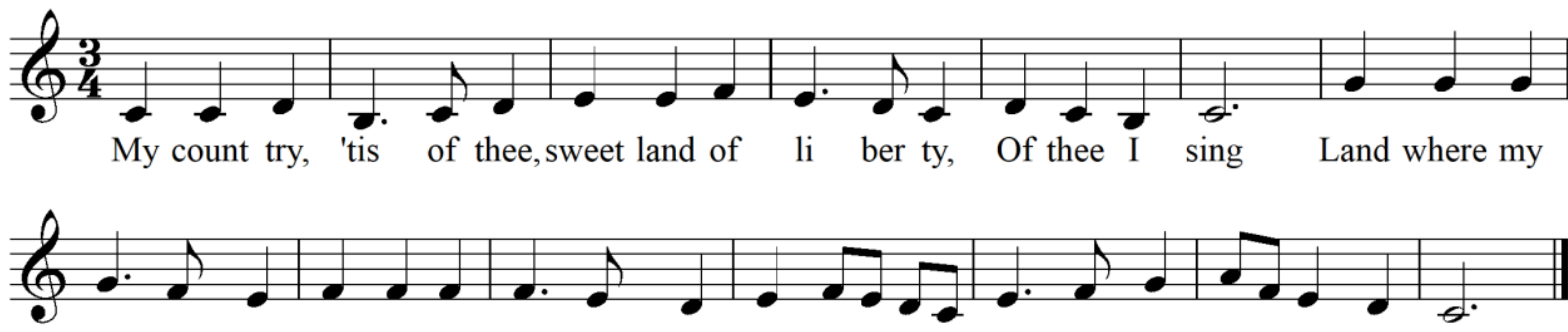

fa thers died,Land of the pil grim's prideFrom ev ry - moun tain side, Let-free dom ring!

Şekil 12. Mutasyon Döneminde Seslerin Sınıflandırılmasına Yönelik Şarkı Örneği (America (My Country Tis of Thee). (ty). https://www.bethsnotesplus.com/2012/09/america-my-country-tis-ofthee.html adresinden 16.05.2020 tarihinde erişilmiştir). 